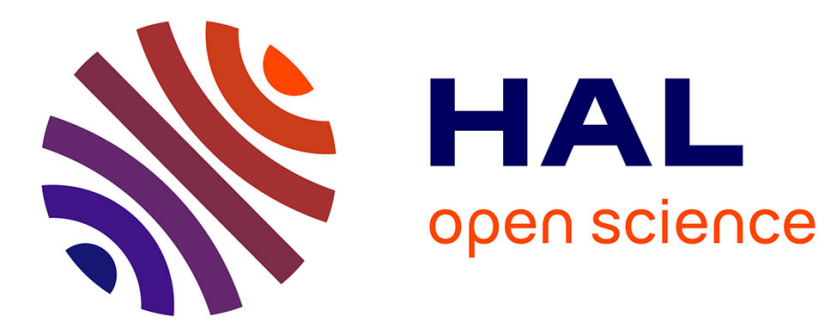

\title{
A Tunable Microwave Source using Nonlinear Magnetostatic Surface Waves in Magnetic Garnet Films
}

S. Jun, J. Pelzl

\section{To cite this version:}

S. Jun, J. Pelzl. A Tunable Microwave Source using Nonlinear Magnetostatic Surface Waves in Magnetic Garnet Films. Journal de Physique IV Proceedings, 1997, 07 (C1), pp.C1-399-C1-400. 10.1051/jp4:19971161 . jpa-00254807

\section{HAL Id: jpa-00254807 https://hal.science/jpa-00254807}

Submitted on 1 Jan 1997

HAL is a multi-disciplinary open access archive for the deposit and dissemination of scientific research documents, whether they are published or not. The documents may come from teaching and research institutions in France or abroad, or from public or private research centers.
L'archive ouverte pluridisciplinaire HAL, est destinée au dépôt et à la diffusion de documents scientifiques de niveau recherche, publiés ou non, émanant des établissements d'enseignement et de recherche français ou étrangers, des laboratoires publics ou privés. 


\title{
A Tunable Microwave Source using Nonlinear Magnetostatic Surface Waves in Magnetic Garnet Films
}

\author{
S. Jun and J. Pelzl \\ Institut für Experimentalphysik III, Ruhr-Universität Bochum, 44780 Bochum, Germany
}

\begin{abstract}
A new type of microwave source is developed by utilizing the sideband where the modulation instability of magnetostatic surface wave takes place. It is found that separation between magnetic garnet film and metallic ground plane and the film thickness affect the operation characteristics of the device. Generation of higher microwave frequency and the operation bandwidth of the device can be controlled by a biasing magnetic field. The experimental results are in accordance with the theoretical predictions.
\end{abstract}

\section{INTRODUCTION}

Nonlinear effects accompanying magnetostatic wave (MSW) propagation in ferromagnetic films have been studied extensively in recent decade. Characteristics of MSW envelop solitons [1-3] and decay processes of traveling MSW [4,5] have shown the promising prospects of nonlinear spin wave applications in signal processing and communication systems. Recent observation of modulation instability of magnetostatic surface waves (MSSW) demonstrates that by improving the MSSW dispersion characteristics, as a result of competition between anomalous dispersion and the nonlinearity of the MSSW, new frequencies can be produced as the satellites of the original input signals[6]. A type of tunable microwave signal generator has been proposed by means of the MSSW modulation instability[7].

This paper concerns characteristics of the microwave source using nonlinear MSSW in magnetic garnet films. The magnetic tunability and the bandwidth of the device are evaluated, and comparison of theoretical prediction with the experimental results is presented.

\section{SIGNAL GENERATION AS A RESULT OF MSSW MODULATION INSTABILITY}

MSSW propagation is excited in a transversely biased $28 \mu \mathrm{m}$-thick and $0.4 \mathrm{~cm}$-wide pure yttrium iron garnet (YIG) film which is flipped onto a pair of identical $50 \mu \mathrm{m}$-wide and $1.3 \mathrm{~cm}$-apart shorted microstrip transducers. Separation between the YIG film and a metallic ground plane $t$ is $254 \mu \mathrm{m}$, i.e., the thickness of the alumina substrate for the transducers. The external magnetic field is $10000 \mathrm{e}$.

For a cw MSSW, onset of modulation instability [8] requires that the frequency shift characterized by a dispersion parameter $\partial^{2} \omega / \partial \mathbf{k}^{2}$, and the frequency shift characterized by a nonlinear parameter $\partial \omega /\left.\partial \phi\right|^{2}$ must have opposite signs, where $\omega, \mathbf{k},|\phi|$ are the MSSW angular frequency, wave number and amplitude, respectively. Once this sign condition (i.e., Lighthill condition [6]) is satisfied and the MSSW power is beyond a threshold for the modulation instability, the traveling MSSW envelope will be modulated with a frequency $f_{\mathrm{s}}$ which can be derived from the nonlinear Schrödinger equation as:

$$
f_{s}=\frac{|\phi|}{2 \pi} \sqrt{-2 \frac{\partial \mathbf{k}}{\left.\partial \phi\right|^{2}} / \frac{\partial^{2} \mathbf{k}}{\partial \omega^{2}}} .
$$

As shown in Fig. 1, the predicted modulation frequencies (the solid curve) agree with the experimental data (the circles) results well. Meanwhile, it is also indicated that the modulation instability can be activated when the MSSW frequency varies 
from $4.84 \mathrm{GHz}$ to $4.88 \mathrm{GHz}$. Consequently, new generated microwave frequency $f_{\mathrm{n}}$ which equals to $f \pm f_{\mathrm{s}}$ can be extracted in this frequency range, where the initial MSSW frequency $f=\omega / 2 \pi$.

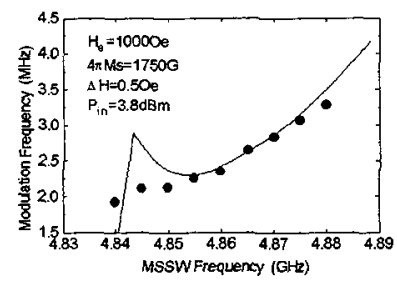

Fig. 1 Modulation frequency as a function of MSSW frequency. YIG thickness $\mathrm{d}=28 \mu \mathrm{m}$, $\mathrm{t}=254 \mu \mathrm{m}$.

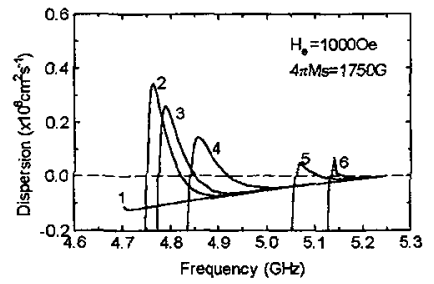

Fig. 2 Dispersion $\partial^{2} \omega / \partial \mathrm{k}^{2}$ versus MSSW frequency. $\mathrm{t}=3000 \mu \mathrm{m}(1), 500 \mu \mathrm{m}(2)$, $400 \mu \mathrm{m}(3), 254 \mu \mathrm{m}(4), 100 \mu \mathrm{m}$ (5), and $80 \mu \mathrm{m}(6)$, respectively.

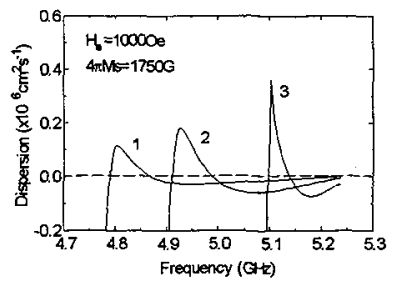

Fig. 3 Influence of YTG thickness on the dispersion $\partial^{2} \omega / \partial \mathrm{k}^{2} . \mathrm{d}=20 \mu \mathrm{m}(1)$, $40 \mu \mathrm{m}(2), 80 \mu \mathrm{m}(3)$, respectively; $\mathrm{t}=254 \mu \mathrm{m}$.

The bandwidth of the nonlinear MSSW device is of considerable technological interest. As the sign of $\partial \omega / \partial|\phi|^{2}$ is always negative for MSSW, the microwave source is applicable only in the frequency range in which $\partial^{2} \omega / \partial \mathrm{k}^{2}>0$. Furthermore, determination of the device bandwidth [7] suggests that the wider the frequency range in which $\partial^{2} \omega / \partial \mathbf{k}^{2}>0$ is, the larger the bandwidth is. Fig. 2 shows influence of the metallic ground plane on $\partial^{2} \omega / \partial \mathrm{k}^{2}$. When the ground plane is far away from the YTG film (for instance, $t=3000 \mu \mathrm{m}$, which is equivalent to the absence of the plane due to the exponential attenuation of $\mathrm{if}$ fields), $\partial^{2} \omega / \partial \mathbf{k}^{2}$ is negative, and the MSSW modulation instability process is forbidden. Introduction of the ground plane can make Lighthill condition satisfied in a limited frequency range as indicated by curves 2 to 6 in Fig. 2 . This property dominates the excitation of the MSSW modulation instability. On the other hand, Fig. 2 turns out that if the ground plane is too close to the YIG film, the frequency range corresponding to the positive $\partial^{2} \omega / \partial \mathrm{k}^{2}$ will shrink. Thus, there exists an optimal separation between the YIG film and the metallic ground plane for the discussed device. As described in Fig. 3, the YIG film thickness also affects the device operation bandwidth significantly. For the case that $t=254 \mu \mathrm{m}$, when the YTG thickness equals to $80 \mu \mathrm{m}$, the allowed frequency range for the modulation instability becomes nearly half of that when the thickness is $20 \mu \mathrm{m}$.

Owing to the MSSW magnetic tunability, operation of the proposed device can be controlled by the bias magnetic field. In Fig. 4, by taking into account Lighthill condition, the frequency range in which the MSSW power is higher than the power threshold for the modulation instability corresponds to the operation range of the device. An increase in the magnetic field can moves the operation range upward to higher frequency, and thus the new generated
frequency will be higher. Furthermore, both the theoretical results in Fig. 4 and

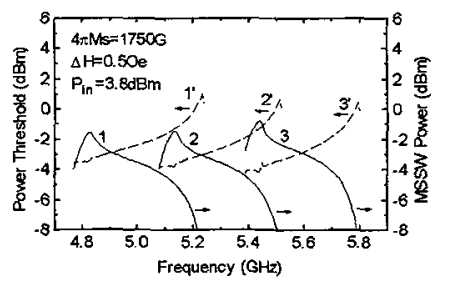

Fig. 4 Dependencies of MSSW power and the power threshold for the modulation instability on the MSSW frequency. Magnetic tunability of the device is shown. Curves 1 and $1^{\prime}$ : $\mathrm{H}_{e}=1000 \mathrm{Oe}$; curves 2 and $2^{\prime}: \mathrm{H}_{e}=11000 \mathrm{e}$; curves 3 and $3^{\prime}: H_{8}=12000$ e.

the experimental measurements shown in Fig. 5 conclude that a linear increase in the device bandwidth can be achieved by increasing the biasing magnetic field.

Acknowledgment: One of the authors (S.J.) is greatly indebted to the support by the Alexander von Humboldt Foundation, Germany.

[1] B. A. Kalinikos, N. G. Kovshikov, and A. N. Slavin, JETP Lett. 38, 413(1983)

[2] M. Chen, M. A. Tsankov, I. M. Nash, and C. E. Patton, Phys. Rev. B 49, 12773(1994)

[3] R. Marcelli, P. De Gasperis, M. Dragoman, and Su Jun, Proc. of 25th Europe. Microwave Conf., Bologna, Italy, 4-7 September 1995, pp. $599-604$

[4] A. M. Mednikov, Sov. Phys. Solid State 23, 136(1981)

[5] A. D. Boardman and S. A. Nikitov, Phys. Rev. B 38, 11444(1988)

[6] S. A. Nikitov, Su Jun, R. Marcelli, and P. De Gasperis, J. Magn. Magn. Mat. 145, L6(1995)

[7] Su Jun, Appl, Phys. Lett., 68, 1996

[8] G. M. Dudko and Yu. A. Filimonov, Sov. Tech. Phys. Lett, 15, 6l(1989)

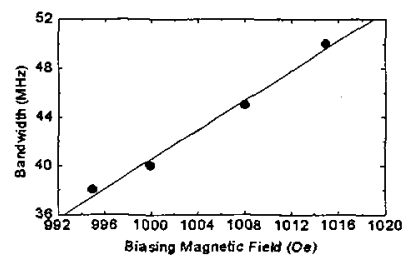

Fig. 5 Variation of the device bandwidth with different biasing magnetic fields. The fitting to the experimental data shows a linear relationship between them. 